\title{
Influence of cathodic current density on properties of ceramic coatings on 6063 aluminum alloy by micro-arc oxidation $\times$
}

\author{
Song Chen ${ }^{1, *}$, Fang Zhang ${ }^{2, *}$, Decai Qin ${ }^{1,2}$, Haijun Tao $^{2}$, Yangyang $^{3}$, Yunshan Bai $^{1}$ \\ ${ }^{1}$ School of Chemistry \& Chemical Engineering, Yancheng Institute of Technology, Yancheng, Jiangsu, \\ 224051, PR China \\ ${ }^{2}$ College of Materials Science and Engineering, Key Laboratory of Materials and Technologies for \\ Energy Conversion, Nanjing University of Aeronautics and Astronautics, Nanjing, 210016, PR China \\ ${ }^{3}$ Special and Key Laboratory of Guizhou Provincial Higher Education for Green Energy-Saving \\ Materials, College of information Engineering, Guizhou Minzu University, Guiyang 550025, P.R. \\ China \\ *E-mail: jsyccs@163.com, zhangfang@nuaa.edu.cn
}

doi: $10.20964 / 110431$

Received: 16 July 2015 / Accepted: 24 February 2016 / Published: 1 April 2016

\begin{abstract}
The ceramic coatings were prepared by a micro-arc oxidation (MAO) process upon 6063 Aluminum Alloy in the environmentally friendly electrolyte of silicate, and the effect of cathodic current density was studied. The results show that cathodic current density plays an important role to obtain a comprehensive performance for the ceramic coating. With the increase of cathodic current density, the color of the coatings gradually changes from light white to brown under natural light. The thickness and the surface micro-hardness of the coatings increase initially and then decrease, the maximum thickness was nearly 5 times thicker than the ordinary one, which is about $13.6 \mu \mathrm{m}$. The friction coefficient and the corrosion resistance of the coatings have the same variation trend with the thickness, the surface micro-hardness increases nearly 8 times, the corrosion resistance is almost 10 times better than that of the substrate in $10 \mathrm{~min}$, and the friction coefficient of the coatings is increases 2 times.
\end{abstract}

Keywords: Aluminum alloy, Micro-arc oxidation, Micro-hardness, Corrosion resistance, Wear resistance

\section{$\underline{\text { FULL TEXT }}$}

(C) 2015 The Authors. Published by ESG (www.electrochemsci.org). This article is an open access article distributed under the terms and conditions of the Creative Commons Attribution license (http://creativecommons.org/licenses/by/4.0/). 